\title{
INSTRUCCIONES A LOS AUTORES
}

1. La Revista Internacional Interdisciplinaria INTERthesis, publicada por el Programa de Postgrado Interdisciplinario en Ciencias Humanas de la Universidad Federal de Santa Catarina (UFSC), recibe artículos inéditos para evaluar, que sean concisos y consistentes, preferencialmente con abordaje interdisciplinario, estableciendo interlocuciones entre diferentes disciplinas, principalmente en áreas temáticas tales como:

- Condición Humana en la Modernidad,

- Estudios de Género y

- Sociedad y Medio Ambiente

Se aceptarán contribuciones en las siguientes modalidades:

a) Artículo: debe ser original, contribución de carácter académico y/o técnicocientífico destinada a divulgar resultados de investigaciones científicas de naturaleza empírica, experimental o conceptual (extensión mínima de 12 y máxima de 18 páginas, incluyendo títulos, resúmenes, tablas, figuras, mapas $y$ referencias).

b) Revisión: evaluación crítica sistematizada de la literatura sobre determinado asunto; se debe mencionar el objetivo de la revisión, especificar (en métodos) los criterios de busca en la literatura y el universo investigado, discutir los resultados obtenidos y proponer estudios en el sentido de llenar los vacíos del conocimiento actual (extensión mínima de 12 y máxima de 18 páginas, incluyendo títulos, resúmenes, tablas, figuras, mapas y referencias).

c) Ensayo: reflexión circunstanciada, con redacción adecuada a una publicación 
d) científica, con mayor libertad por parte del autor para defender determinada posición, que vise a profundizar la discusión o que presente nueva contribución/abordaje con respecto a un tema relevante (extensión mínima de 12 y máxima de 18 páginas, incluyendo títulos, resúmenes, tablas, figuras, mapas y referencias).

e) Reseña: análisis crítico sobre libro publicado en los últimos dos años (extensión máxima de 6 páginas, con las mismas configuraciones que se solicita al texto, incluyendo referencia bibliográfica completa en la cabecera).

2. Artículo sometido por alumno(a) de postgrado (Maestría y/o Doctorado) solamente será aceptado si es escrito en coautoría con el(la) Orientador(a), como lo sugiere la Coordinación de Perfeccionamiento de Personal de Nivel Superior - CAPES.

3. Todos los artículos son apreciados por dos evaluadores, a través del sistema Blind Review, o sea, evaluación ciega, y caso se necesite será enviado todavía a un tercer evaluador.

4. Los originales podrán ser:

a) aceptados/aprobados para publicación sin restricciones;

b) aprobados si son cumplidas las modificaciones sugeridas, sin necesidad de retornar al revisor;

c) aprobados si son cumplidas las modificaciones sugeridas, con necesidad de relectura por el revisor;

d) parcialmente rechazados, cuando necesita de amplia revisión y deberá ser sometido para una nueva evaluación;

e) rechazados.

5. Es de responsabilidad del(de los) autor(es) hacer las debidas correcciones gramaticales en el texto enviado, como también cuidar de la obtención de autorización de derechos autorales con relación al uso de imágenes, figuras, tablas, métodos etc., junto a otros autores o editores, cuando ese sea el caso. 
6. El texto aceptado para publicación en los idiomas portugués o español que desee ser traducido al inglés, se sugiere la corrección del American Journal Experts (www.journalexperts.com), cuyo costo será por cuenta de los autores.

7. La Revista se reserva el derecho de evitar la publicación de un mismo autor en intervalos menores a cuatro ediciones.

8. El contenido de los trabajos es de responsabilidad exclusiva de sus autores.

9. Cuando las alteraciones se refieran apenas a aspectos gramaticales, ortográficos y de orden normativa, con vistas a mantener la homogeneidad de la publicación, editores y asistentes tienen el derecho de hacer las modificaciones necesarias, respetando el estilo del autor. En los demás casos, el autor alterará el texto conforme lo que fuera solicitado, reenviándolo en el plazo máximo estipulado por el editor que podrá ser de hasta 30 días para relectura/nueva evaluación.

10. Cuando se sugiera en la 'evaluación por pares' revisión gramatical más precisa del manuscrito, podrá ser sugerido a los autores que se responsabilicen por la revisión a ser realizada por un profesional diplomado en el idioma correspondiente, observando las normas del idioma culto.

11. Los artículos y demás trabajos publicados por la INTERthesis pasan a ser propiedad de la Revista. La impresión total o parcial de los textos es permitida desde que se mencione el nombre de la Revista, la edición, fecha de publicación, dirección electrónica y fecha de consulta.

12. Los textos pueden ser presentados en tres idiomas: portugués, español o inglés.

13. Los artículos deberán ser enviados conforme las normas de presentación de artículos de la Asociación Brasileña de Normas Técnicas (ABNT) - NBR6022 de mayo de 2003.

14. Para los artículos en lengua española o inglesa, los autores deberán utilizar las normas brasileñas de la Asociación Brasileña de Normas Técnicas (ABNT), conforme expuesto en el ítem anterior. 
15. Anonimato:

a) En el texto sometido para evaluación NO debe constar el(los) nombre(s) del(de los) autor(es).

b) Se solicita al(a los) autor(es) que antes de someter el texto, retire el(los) nombre(s) de autoría o cualquiera identificación del texto o cualquier identificación del archivo enviado, inclusive en las propiedades de 'Word'.

16. Sumisión electrónica: Los artículos deberán ser remetidos a través de la plataforma:

http://www.periodicos.ufsc.br/index.php/interthesis/about/submissions\#onlineSub $\underline{\text { missions }}$

17. El archivo que contenga el manuscrito, que será anexado (transferido), durante el proceso de envío, no podrá ultrapasar el tamaño de 3MB.

18. Si el autor ya está registrado en el sistema, es necesario solamente hacer Login y seguir los pasos para enviar el trabajo. Si el autor todavía no está registrado, debe usar el link Acesso de la página inicial, y luego el link Não está cadastrado? Cadastre-se no sistema http://www.periodicos.ufsc.br/index.php/interthesis/user/register, completar el formulario con las informaciones requeridas.

19. A continuación, utilice el link Autor y comience el proceso de envío del artículo. Son cinco pasos, acuérdese de guardar en el final de cada etapa:

Inicio: elegir en cual categoría se ubica el texto (Artículo, Revisión de Literatura, Ensayo o Reseña) e indicar el idioma del texto.

a) Confirme marcando en la caja de selección que la sumisión está en conformidad con las condiciones de la Revista antes de proseguir al $2^{\circ}$ paso del proceso.

b) Transferencia del manuscrito: transferir el archivo en .doc o .docx, recordando que deben remover cualquier tipo de identificación de autoría.

c) Inclusión de metadatos: completar los datos de autoría, incluyendo el resumen 
de biografía. Caso tenga más de un autor, abrir el link "incluir autor" y completar los datos, completando los campos de título y resumen en letra minúscula. Completar los campos de indexación y palabras clave es ítem obligatorio.

d) Transferencia de documentos complementarios: esta etapa es opcional. Pueden ser anexados documentos como autorizaciones de publicación y uso de fuentes o complementos al artículo como tablas, figuras, gráficos, mapas y fotos inherentes al texto enviado.

e) Confirmación: confirmación de que el archivo fue anexado al sistema y conclusión de la sumisión.

\section{Características generales del texto:}

El texto sometido debe ser digitado en Word 2003 (o superior).

La formatación del texto y de las referencias debe seguir las especificaciones abajo:

\section{1) Formatación del texto}

a. Como formato y características generales, el texto debe ser/tener:

b. Digitado en Word 2003 (o superior);

c. Espaciado 1,5 cm;

d. Alineado justificado;

e. Fuente Arial 12;

f. Papel en formato A4;

g. Márgenes superior/inferior - derecha/izquierda $=2,5 \mathrm{~cm}$;

h. Sangría sobre la primera línea del párrafo $=1,25 \mathrm{~cm}$;

i. En lo posible, evite notas de pie de página. En caso de utilizarlas, deben ir al final de la página, en numeración continua, fuente Arial 10, espacio 
simple, alineado justificado.

\section{2) El artículo debe ser elaborado en esta secuencia:}

\section{Elementos pre textuales (1ª página)}

a. Título y subtítulo (si hubiera) en el idioma del texto;

I. En el encabezado, debe estar en alineado justificado, en letras mayúsculas, letra negrita, fuente Arial 12 , espacio simple y tener no más de 15 palabras.

b. Resumen en el idioma del texto;

I. El resumen debe tener un mínimo de $\mathbf{1 0 0}$ y un máximo de $\mathbf{2 5 0}$ palabras, exponiendo el abordaje principal del texto.

II. Debe ser claro y conciso, en un párrafo único, alineamiento justificado, fuente Arial 12, espacio simple, conteniendo objetivo, metodología, resultados y conclusiones, siguiendo las normas de la ABNT NBR6028/2003;

c. Palabras clave en el idioma del texto;

I. Deben ser presentadas 05 (cinco) palabras clave que mejor representen el asunto del artículo. Las palabras deben ser separadas por punto, como en el siguiente ejemplo:

Palabras clave: Una palabra. Dos. Tres. Cuatro. Cinco palabras.

\section{Elementos textuales (Cuerpo de texto del artículo)}

a. El manuscrito debe ser presentado en fuente Arial 12, espacio $1,5 \mathrm{~cm}$, alineamiento justificado y párrafo con sangría de $1,25 \mathrm{~cm}$ en la primera línea. Se sugiere que el texto obedezca la siguiente secuencia:

b. Introducción, Metodología o Procedimientos metodológicos/operacionales, Capítulos o subdivisiones del cuerpo del trabajo, Consideraciones Finales o Conclusiones, y Referencias. Títulos de las secciones en letra mayúscula y 
negrita.

\section{Tablas, figuras, gráficos y mapas}

a. Cualquier tipo de ilustración presentada debe ser incorporada en el texto, lo más próximo posible de la parte que se pretende ilustrar, evitando expresiones como "Figura a seguir" o "tabla abajo" y utilizando siempre la numeración: "conforme tabla 5", "de acuerdo con el gráfico $10 "$.

b. El tamaño de las ilustraciones no debe ultrapasar los márgenes.

c. Las tablas con informaciones estadísticas deben seguir las normas de presentación de tablas del IBGE (Instituto Brasileño de Geografía y Estadística)/1993. Se define tabla como la forma no discursiva de presentar informaciones, en la cual se destacan los números e informaciones estadísticas.

d. La identificación de una tabla debe ser hecha a través de números arábicos precedidos de la palabra Tabla y seguidos de su título. Esta identificación deberá aparecer arriba de la referida tabla.

e. La tabla no es cerrada con líneas en los lados derecho e izquierdo, o sea, no hay delimitación lateral. Se recomienda que las tablas presentes en el artículo posean uniformidad gráfica, cuanto a colores y layout, utilizando fuente Arial 10 para los datos presentados, o, en el caso de fuente externa, puede ser presentada como imagen JPEG. La fuente debe ser indicada abajo de la misma, conforme el ejemplo a seguir:

Tabela 1 - Pessoas residentes em domicilios particulares, por sexo e situaçäo do domicílio - Brasil - 1980

\begin{tabular}{|c|c|c|c|c|}
\hline & $\begin{array}{c}\text { Situaçăo } \\
\text { do } \\
\text { domicilio }\end{array}$ & Total & Mulheres & Homens \\
\hline Total & & 117960301 & 59595332 & 58364969 \\
\hline Urbana & & 79972931 & 41115439 & 38857492 \\
\hline Rural & & 37987370 & 18479893 & 19507477 \\
\hline
\end{tabular}


f. Las demás ilustraciones, como dibujos, mapas, organigramas, fotografías y otras, deben ser incluidas en el texto en formato JPEG y también en documentos complementares independientes, a través del sistema online de la Revista, en el mismo formato. La identificación aparece en la parte inferior de la imagen, con la numeración de orden siendo la misma identificada en el texto. La fuente de información debe venir en seguida. La formatación de la leyenda debe ser en fuente Arial 10 , en negrita.

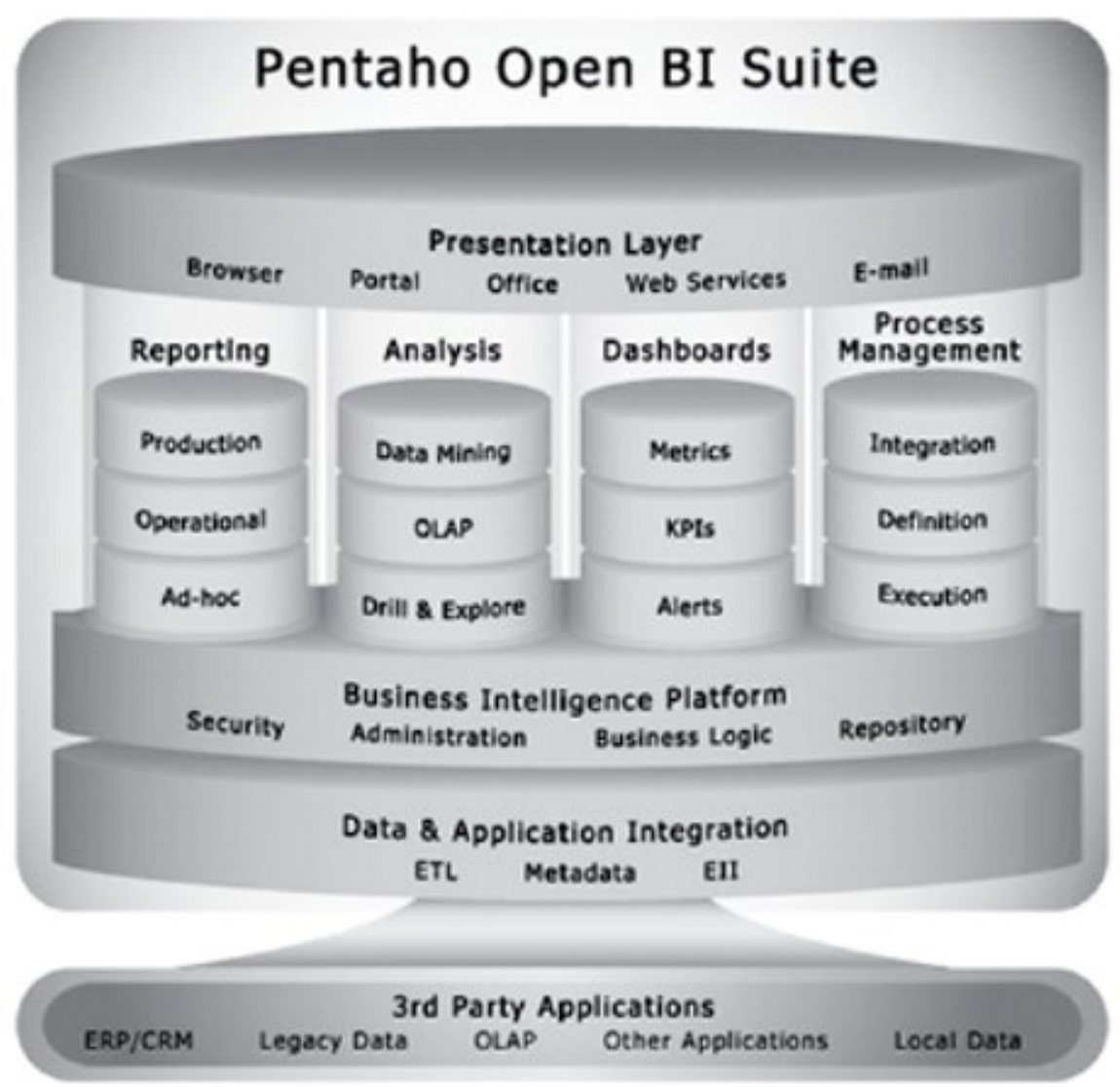

Figura 1 - Componentes de la Suite.

Fuente: Tessler e Sales (2008) 


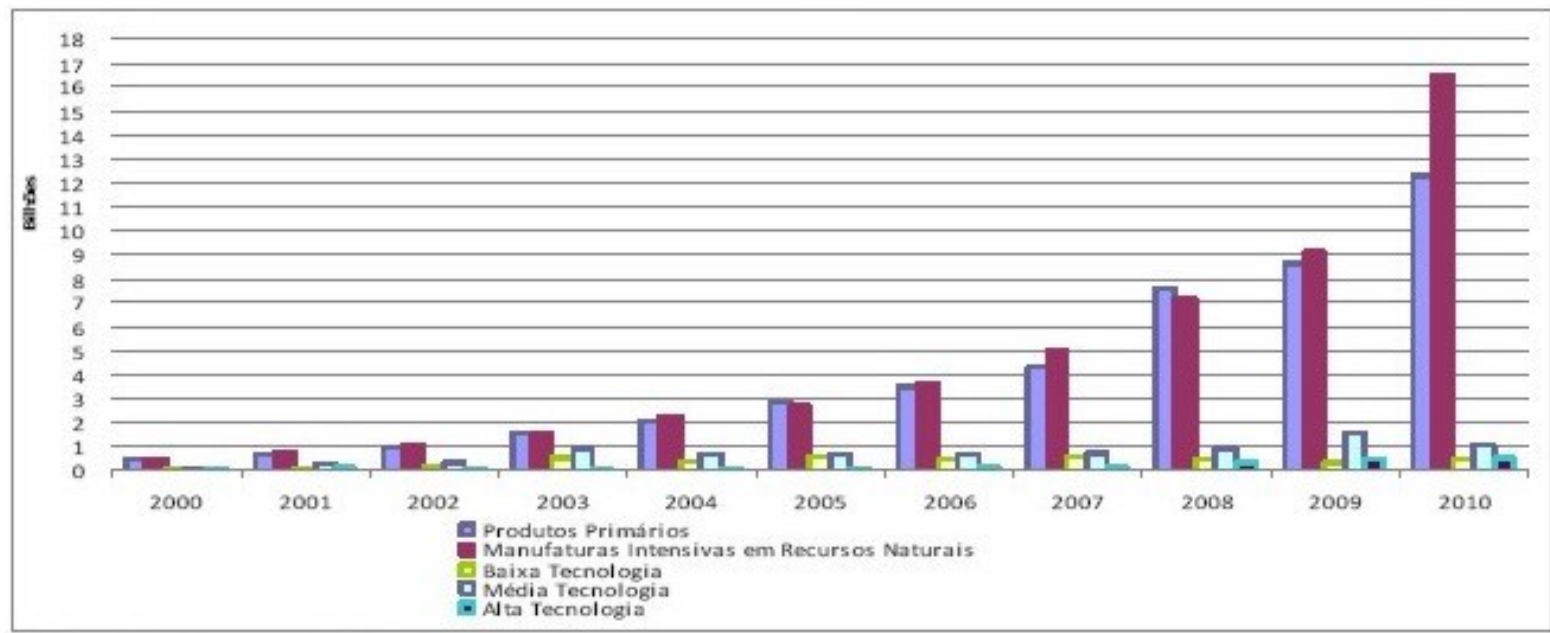

Gráfico 5 - Pauta exportadora de Brasil con China, por intensidad tecnológica del producto. Fuente: UNContrade.

g. Las fuentes de información utilizadas para cualesquier tipos de ilustración, excepto cuando sea elaboración del propio autor, deberán ser referenciadas al final del artículo.

\section{Citas}

a. Las citas directas, teniendo hasta tres renglones, deben estar entre doble comillas, en el cuerpo del texto. Las citas deben ser elaboradas conforme la norma de la ABNT NBR10520/2002, usando obligatoriamente el sistema autor-fecha.

Ejemplos:

Carvalho y Schmitz (1990, p.149) afirman que "até os anos 70 os princípios do fordismo guiaram internacionalmente a administração na indústria automobilística e em outras indústrias de produção em massa".

O

"Até os anos 70 os princípios do fordismo guiaram internacionalmente a administração na indústria automobilística e em outras indústrias de produção em massa" (CARVALHO; SCHMITZ, 1990, p.149). 
b. Las citas directas con más de tres renglones (cita larga) deben ser destacadas:

I. con sangría de $\mathbf{4} \mathrm{cm}$ de margen izquierdo;

II. en fuente Arial 10;

III. espacio simple;

IV. espacio antes y después de $12 \mathrm{pt}$;

V. sin comillas;

VI. en caso de omisión de texto, utilizar corchetes [...]

Ejemplo:

São abundantes os sinais e marcas de modificações radicais em processos de trabalho, hábitos de consumo, configurações geográficas e geopolíticas, poderes e práticas do Estado etc. [...] ainda vivemos uma sociedade em que a produção em função de lucros permanece como princípio organizador básico da vida econômica. Portanto, precisamos de alguma maneira representar todos os grandes eventos ocorridos desde a primeira grande recessão do pós-guerra, em 1973, maneira que não perca de vista o fato de as regras básicas do modo capitalista de produção continuarem a operar como forças plasmadoras invariantes do desenvol vimento históricogeográfico (HARVEY, 2002, p.117).

Elementos post textuales (después del término del artículo, antes de las Referencias)

a) Título y subtítulo (si hubiera) en lengua extranjera (inglés y español);

b) Resumen en lengua extranjera (inglés y español);

i. Abstract y Resumen, en alineamiento justificado, fuente Arial 12, espacio simples.

c) Palabras clave en lengua extranjera (inglés y español)

i. Keywords y Palabras clave, en fuente Arial 12, espacio simple, alineamiento justificado, deben ser separadas por punto e iniciadas con letra mayúscula. 


\section{Referencias}

a) En el ítem de las 'Referencias' solamente deben constar los textos, artículos y documentos que fueron utilizados en el cuerpo del texto. Utilizar la norma NBR 6023/2002 para la elaboración de las referencias.

b) En relación al primer nombre del autor, se debe optar por escribirlo por extenso o utilizar solamente la inicial del primer nombre, debiéndose seguir un único modo para todas las obras referenciadas.

c) La Revista recomienda que el veinte por ciento (20\%) de las referencias bibliográficas y/o citaciones sean artículos que se encuentren en las bases internacionales, como por ejemplo: SciELO, Scopus, o ISI Web of Knowledge, con menos de diez años.

d) Se solicita que en el artículo se evite la auto citación, citación de monografías, anales, resúmenes expandidos, periódicos y revistas.

e) Para un mismo autor referenciado en secuencia, se debe repetir su nombre, no utilizando subrayado.

f) Las referencias son alineadas solamente al margen izquierdo del texto y de forma a identificarse individualmente cada documento, en espacio simple y separadas entre sí por espacio doble. Deben ser presentadas en orden alfabético.

\section{Libro}

\section{Cuando hay sólo un autor:}

FACHIN, Odília. Fundamentos de metodologia. 4. ed. São Paulo: Saraiva, 2003. SCHÜTZ, Edgar. Reengenharia mental: reeducação de hábitos e programação de metas. Florianópolis: Insular, 1997.

\section{Cuando hay dos o tres autores:}

LAKATOS, E. M.; MARCONI, M. de A. Metodologia científica. 2. ed. São Paulo: Atlas, 1991.

CASTILLO, G.; KOSTOF, S.; TOBIAS, R. A history of architecture: settings and 
rituals. Oxford: Oxford University Press, 1995.

Cuando hay más de tres autores:

CAJUEIRO, Daniel Oliveira et al. Modelo de localização industrial para o planejamento de um pólo de alta tecnologia. Brasília: IPEA, 2005. 18p. (Texto para discussão, 1.134).

MAGALHÃES, A. D. F. et al. Perícia contábil. 3. ed. São Paulo: Atlas, 2001.

BRITO, E. V. et al. Imposto de renda das pessoas físicas: livro prático de consulta diária. São Paulo: Frase Editora, 1996.

Cuando hay organizador (Org.), coordinador (Coord.) o editor (Ed.):

BOSI, A. (Org.). O conto brasileiro contemporâneo. 6. ed. São Paulo: Cultrix, 1989.

VERSIANI, Flávio Rabelo; BARROS, José Roberto Mendonça de (Org.). Formação econômica do Brasil: a experiência da industrialização. São Paulo: Saraiva, 1978.

Cuando no aparece la ciudad de publicación:

KRIEGER, Gustavo; NOVAES, Luís Antonio; FARIA, Tales. Todos os sócios do presidente. 3. ed. [S.I.]: Scritta, 1992. 195 p.

Cuando no aparece el nombre de la editora:

VALÊNCIA, I. Das mulheres e das flores. Belo Horizonte: [s.n.], 1974.

Cuando no hay fecha de la edicción: siempre debe ser indicada una fecha, sea de publicación, de distribución, del copyright, de impresion o otra. Si ninguna fecha puede ser determinada, se coloca una fecha aproximada entre corchetes [ ], como sigue:

[1971] fecha cierta, pero no indicada en el material

[1989?] fecha probable de la publicación

[ca1965] fecha aproximada de la publicación

Cuando el autor es una entidad:

BRASIL. Ministério da Educação. Secretaria de Administração Geral. A educação no Brasil na década de 80. Brasília: MEC, 1990. 106 p.

ASSOCIAÇÃO BRASILEIRA DE NORMAS TÉCNICAS. NBR 6023: Informação e documentação. Rio de Janeiro: ABNT, 2000. 3 p. 
PREFEITURA MUNICIPAL DE CASCAVEL Recuperação ambiental da bacia hidrográfica do Rio Cascavel. Cascavel: FUNDETEC. 1995. 164 p.

\section{Cuando la obra tiene título y subtítulo:}

CERTEAU, M. de. Histoire et psychanalyse: entre science et fiction. Paris: Gallimard, 1987.

\section{Autoría desconocida:}

Cuando no existe el nombre del autor, la primera palabra significativa del título es escrita en letra mayúscula. No se usa el término 'anónimo'. Ejemplo:

O PENSAMENTO vivo de Nietzsche. São Paulo: Martin Claret, 1991. 110p.

\section{Capítulo de libro}

MOURA, Rosa. Políticas públicas urbanas: ausências e impactos. In: MENDONÇA, Francisco (Org.). Impactos socioambientais urbanos. Curitiba: Ed. UFPR, 2004. p.149-168.

PINHEIRO, Armando Castelar; GIAMBIAGI, Fabio; GOSTKORZEWICZ, Joana. O desempenho macroeconômico do Brasil nos anos 90. In: GIAMBIAGI, Fabio; MOREIRA, Maurício Mesquita (Org.). A economia brasileira nos anos 90. Rio de Janeiro: BNDES, 1999. p.11-41.

LIMA, L. de O. Ativação dos processos didáticos na escola secundária. In: LIMA, L. A escola secundária moderna: organização, métodos e processos. Rio de Janeiro: Forense-Universitária, 1976. cap. 12, p. 213-234.

HORTA, J. S. B. Planejamento educacional. In: MENDES, Dumerval Trigueiro (Org.). Filosofia da Educação Brasileira. Rio de Janeiro: Civilização Brasileira, 1991. p.195-239.

\section{Artículo em periódico}

TORRES, Haroldo da Gama et al. Pobreza e espaço: padrões de segregação em São Paulo. Estudos Avançados, São Paulo, v. 17, n. 47, p. 97-128, jan./abr. 2003.

ARAÚJO, S. M. P. Indústria automobilística e sindicato: atuação renovada no Paraná dos anos 2000. Cadernos do CRH, Salvador, v. 19, n. 46, p. 49-62, 2006.

SCHNEIDER, Sergio; BLUME, Roni. Ensaio para uma abordagem territorial da ruralidade: em busca de uma metodologia. Revista Paranaense de Desenvolvimento, Curitiba, n. 197, p. 109-135, jul./dez. 2004.

AZZONI, Carlos R.; CARMO, Heron E. do; MENEZES, Tatiane. Comparações da paridade de poder de compra entre cidades: aspectos metodológicos e aplicação ao caso brasileiro. Pesquisa e Planejamento Econômico, Rio de Janeiro, v. 33, n. 1, 
p. 91-126, abr. 2003.

\section{Disertación y Tesis}

\section{Disertación de maestría:}

RODRIGUES, M. V. Qualidade de vida no trabalho. 1989. 180 f. Dissertação (Mestrado em Administração) - Faculdade de Ciências Econômicas, Universidade Federal de Minas Gerais, Belo Horizonte, 1989.

\section{Tesis de doctorado:}

DELGADO, Paulo Roberto. Precarização do trabalho e condições de vida: a situação da Região Metropolitana de Curitiba nos anos 90. 2001. 163 f. Tese (Doutorado) - Universidade Federal do Paraná, Curitiba, 2001.

FANTUCCI, I. Contribuição do alerta, da atenção, da intenção e da expectativa temporal para o desempenho de humanos em tarefas de tempo de reação. 2001. 130 f. Tese (Doutorado em Psicologia) - Instituto de Psicologia, Universidade de São Paulo, São Paulo, 2001.

\section{Acceso vía Internet}

\section{Artículo de Internet con autor:}

MOULIN, Carolina. Os direitos humanos dos humanos sem direitos: refugiados e a política do protesto. Rev. bras. Ci. Soc., São Paulo, v. 26, n. 76, jun. 2011 .

Disponível em: <http://www.scielo.br/scielo.php?script=sci_arttext\&pid=S010269092011000200008\&lng=pt\&nrm=iso>. Acesso em: 16 dez. 2011. http://dx.doi.org/10.1590/S0102-69092011000200008.

CAPITANI, Daniel Henrique Dario; MIRANDA, Sílvia Helena Galvão de; FILHO, João Gomes Martines. Determinantes da demanda brasileira por importação de arroz do Mercosul. Rev. Econ. Sociol. Rural, Brasília, v. 49, n. 3, set. 2011. Disponível em: $<$ http://www.scielo.br/scielo.php?script=sci_arttext\&pid=S0103$20032011000300002 \&$ Ing=pt\&nrm=iso>. Acesso em: 27 dez. 2011. http://dx.doi.org/10.1590/S0103-20032011000300002.

SCAFFO, Maria Fátima; FARIAS, Francisco Ramos. A transmissão dos protocolos de gênero como dispositivo de submissão feminina à violência conjugal.

INTERthesis, Florianópolis, v. 8, n. 2, p. 134-159, Jul./Dez. 2011 Disponível em: $<$ http://www.periodicos.ufsc.br/index.php/interthesis/article/view/18071384.2011v8n2p134/20572 > Acesso em: 28 dez. 2011. DOI:10.5007/1807$1384.2011 \mathrm{v} 8 \mathrm{n} 2 \mathrm{p} 134$

MONT'ALVAO, Arnaldo. Estratificação educacional no Brasil do século XXI. Dados, Rio de Janeiro, v. 54, n. 2, 2011. Disponível em: <http://www.scielo.br/scielo.php?script=sci_arttext\&pid=S0011- 
52582011000200006\&lng=pt\&nrm=iso>. Acesso em: 28 dez. 2011. http://dx.doi.org/10.1590/S0011-52582011000200006.

COSTA. M. Agronegócio: o motor da economia brasileira e o dinamismo da economia paranaense. Agronline.com.br. Disponível em:

<http://www.agronline.com.br/ artigos/artigo.php?id=331>. Acesso em: 10 mar. 2011.

BARBOSA, Lucia Martins et al. A representação social do professor sob o ponto de vista do aluno. Revista Aprender Virtual, Marília, dez. 2003. Disponível em: $<$ http://www.aprendervirtual.com/ver_noticia.php?codigo $=32$ >. Acesso em:

02 fev. 2004.

\section{Artículo de Internet sin autor específico:}

CIÊNCIA DA INFORMAÇÃO. Brasília, v.26. n.3, 1997. Disponível em: <http://www.ibict.br/cionline >. Acesso em: 19 mai. 1998.

\section{Entrada de diccionario}

ÉTICA. In: FUNDAÇÃO GETÚLIO VARGAS. Instituto de documentação. Dicionário de ciências sociais. Rio de Janeiro: FGV, 1986. p. 433-435.

Universidade Federal de Santa Catarina - UFSC

Centro de Filosofia e Ciências Humanas - CFH

Programa de Pós-Graduação Interdisciplinar em Ciências Humanas - PPGICH

\section{Editores:}

Selvino Assmann, Silmara Cimbalista y Javier Vernal

http://www.periodicos.ufsc.br/index.php/interthesis/index

Correo electrónico: interthesis@gmail.com 